\title{
Clinical effect of intramuscular onabotulinumtoxinA in iliopsoas and adductor muscles in patients with coxarthrosis: A case series analysis
}

\author{
Sofía Durán-Hernández ${ }^{1}$, Nayar Durán-Hernández ${ }^{2}$, Martha Carnalla-Cortés ${ }^{2}$, Juan Carlos Flores-Vázquez ${ }^{2}$ and Ramón Cuevas-Trisán $^{3 *}$ \\ ${ }^{1}$ Hospital General Tacuba, ISSSTE. México DF \\ ${ }^{2}$ Laboratorio Inmunoquímica I, Departamento de Inmunología, ENCB, IPN. México DF \\ ${ }^{3} \mathrm{PM} \& \mathrm{R}$ Service, VA Medical Center West Palm Beach, FL, USA
}

\begin{abstract}
Background: Degenerative joint disease of the hip (coxarthrosis) is a highly prevalent condition in the adult population. Conservative management measures often provide suboptimal results with many patients requiring total hip arthroplasty. More efficacious conservative management approaches are needed.

Aim: To assess the clinical effect of the application of onabotulinumtoxinA (BoNT-A) to the iliopsoas and adductor brevis muscles in patients with coxarthrosis.

Patients and methods: Forty patients with diagnosis of coxarthrosis of various severities according the Kellgren-Lawrence classification were enrolled. A single dose of $100 \mathrm{U}$ of BoNT-A per muscle (iliopsoas and adductor brevis) was applied. Pain intensity using the Visual Analogue Scale (VAS) and the Western Ontario and McMaster Universities Osteoarthritis Index (WOMAC) were measured on day 0 and day 90.

Results: Most of the patients were overweight and had moderate coxarthrosis (grade II) in a significantly higher proportion than grade $\mathrm{I}(\mathrm{P}=0.032)$ and grade $\mathrm{IV}$ $(\mathrm{P}=0.003)$. We observed a significant decrease in reported pain scores from 8 before BoNT-A application to 3 at 90 days after the application $(\mathrm{P}<0.001)$. There was also a significant WOMAC index decrease from 67 to 27 points $(\mathrm{P}<0.001)$.

Conclusion: This pilot investigation showed that the application of BoNT-A to the iliopsoas and adductor brevis muscles may be an effective therapeutic approach in patients with symptomatic coxarthrosis, reducing pain and improving functionality without reported adverse effects.
\end{abstract}

\section{Introduction}

The current non-pharmacologic treatment recommendations for coxarthrosis, according to the American College of Rheumatology and the Osteoarthritis Research Society Internationale, include cardiovascular, aquatic or land-based exercises, weight loss (if applicable), use of thermal agents and the use of walking aids when necessary. The pharmacologic treatment includes oral nonsteroidal anti-inflammatory drugs, acetaminophen, tramadol and intra-articular corticosteroid injections [1,2].

It is estimated that over $90 \%$ of patients with symptomatic coxarthrosis will end up in arthroplasty [3], with the incidence increasing in younger populations [4], hence the importance to find new effective non-surgical approaches to delay the need for surgery or improve the quality of life of patients who may not be candidates for surgery.

Botulinum neurotoxin type A (BoNT-A) has been shown to decrease the release of acetylcholine from pre-synaptic terminals and to possibly modulate the release of other neurotransmitters into the synaptic space resulting in a flaccid paresis and other effects of pain modulation [5]. Several studies have shown the effectiveness of BoNT-A in myofascial pain syndromes, chronic migraine, and neuropathic pain [6-8].

In 2010, Marchini, et al. reported some provocative preliminary results regarding clinical improvement in patients with coxarthrosis after application of BoNT-A (abobotulinumtoxinA) to the adductor longus and adductor magnus muscles $[9,10]$. This investigation is partially based on a procedure described over 5 decades ago. In 1955, Voss described a new surgical procedure for the treatment of osteoarthritis of the hip, the so-called temporary hanging hip ("temporare Hengehufte") which was based on the principle that muscles around the joint are in a state of increased tension and may be an important contributing factor in the development of coxarthrosis. He theorized that under this increased muscular tension, the articular cartilage is exposed to an abnormal pressure, causing a so-called pressure osteoarthritis. Accordingly, he introduced a surgical technique to interrupt this condition of abnormal muscle tension. The technique involved in part, tenotomies of the anterior iliac spine muscles and adductors. Thereby the pressure in the joint would decrease and the cartilage would be afforded a possibility for regeneration. In this pilot study we explore the effects of BoNT-A application to the iliopsoas and adductor brevis muscles to medically simulate part of the effect of the Voss surgical technique [11].

Correspondence to: Ramón Cuevas-Trisán, MD, Chief, PM\&R Service, VA Medical Center West Palm Beach, FL, USA; E-mail: ramon.cuevasmd@gmail.com

Key words: coxarthrosis, onabotulinumtoxinA, Osteoarthritis Research

Received: April 16, 2018; Accepted: April 22, 2018; Published: May 05, 2018 


\section{Patients and Methods}

This open label prospective pilot trial was approved by of the Institutional Review Board of Tacuba General Hospital, ISSSTE with the registration number 035-16. All patients signed an informed consent before enrolling in the study. A non- probabilistic convenience sample of 40 consecutive patients with diagnosis of coxarthrosis according the Kellgren-Lawrence criteria [12] were recruited from an outpatient Physical Medicine and Rehabilitation clinic from 2014 to 2016. All these patients had previously failed conservative management with physical therapy.

\section{Botulinum toxin type A (BoNTX-A) Injections}

A single dose of $100 \mathrm{U}$ per muscle of BoNT-A (onabotulinumtoxinA - Allergan, Inc) reconstituted with $1 \mathrm{ml}$ of $0.9 \%$ preservative-free saline solution was injected into the iliopsoas and adductor brevis muscles using surface anatomical landmarks. All injections were performed by the same physiatrist.

\section{Injection technique}

Iliopsoas: with the patient in supine position and the leg in neutral anatomical position, the anterior superior iliac spine and the femoral pulse were identified by palpation. Needle insertion was halfway between the two, just distal to the inguinal ligament and 3-3.5 cm deep depending on the body habitus.

Adductor brevis: with the patient in supine position and the hip joint slightly flexed and abducted, the tendon at the origin on the pubic tubercle was palpated and injected 4 finger breaths $(7-8 \mathrm{~cm})$ distal from the origin and 3-5 $\mathrm{cm}$ deep through the adductor longus muscle [13].

\section{Pain and osteoarthritis index}

These variables were measured at day 0 (prior to injection) and day 90. The Visual Analogue Scale (VAS) was used for pain intensity evaluation [14] and the Western Ontario and McMaster Universities Osteoarthritis Index (WOMAC) was used as a measure of function [15].

\section{Statistical analysis}

Wilcoxon signed-rank test were used for comparison of before and after medians (VAS, WOMAC). Chi square and Fisher's exact test were used for frequencies in demographic variables. Analyses were performed in SigmaPlot and GraphPad Prism software, with $\mathrm{p}$ value set at 0.05 .

\section{Results}

There was a significant difference $(\mathrm{P}<0.001)$ in the number of women, 29, and men, 11; therefore, we analyzed each variable between them but no significant differences were observed as shown in Table 1. Most of the patients were overweight and had grade II coxarthrosis in a significantly higher proportion than grade I $(\mathrm{P}=0.032)$ and grade IV $(\mathrm{P}=0.003)$, as shown in Figure $1 \& 2$.

Figure 3 shows a significant decrease in pain observed using the VAS score from a median of 8 points before BoNT-A application to a median of 3 points 90 days after the application $(\mathrm{P}<0.001)$. As for the WOMAC index (Figure 4), a significant decrease from 67 to 27 points was observed $(\mathrm{P}<0.001)$. Measurements were performed at 90 days based on the known approximate duration of effect of onabotulinumtoxinA.

We had some concerns regarding the potential of the BoNT-A injections causing significant weakness or functional deficits in some

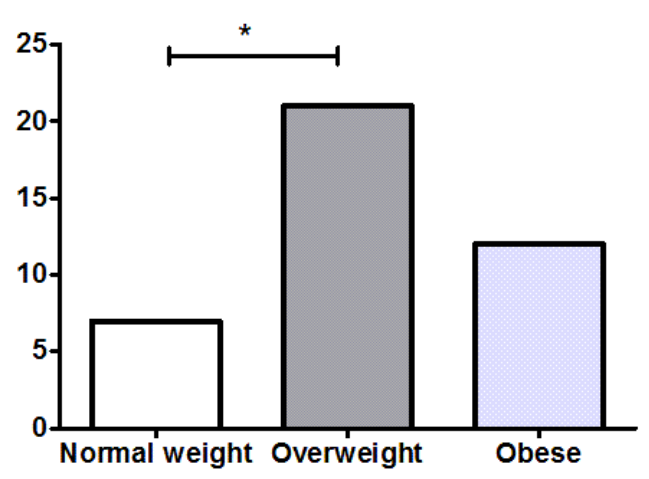

Figure 1. Body Mass Index of the patients in day $0 .{ }^{*} \mathrm{P}<0.01$

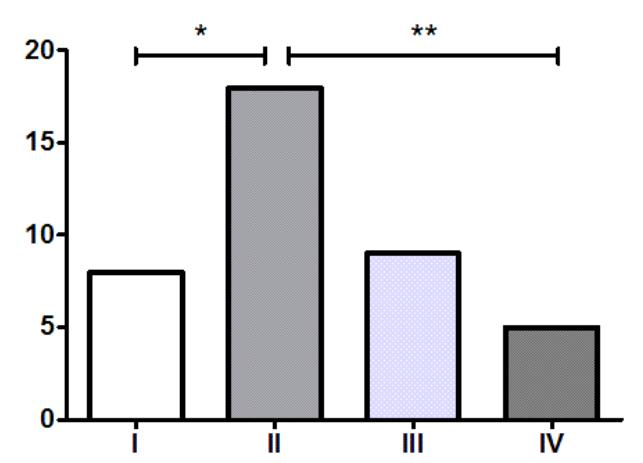

Figure 2. Coxarthrosis grade according to Kellgren and Lawrence. ${ }^{*} \mathrm{P}<0.05,{ }^{*} \mathrm{P}<0.01$

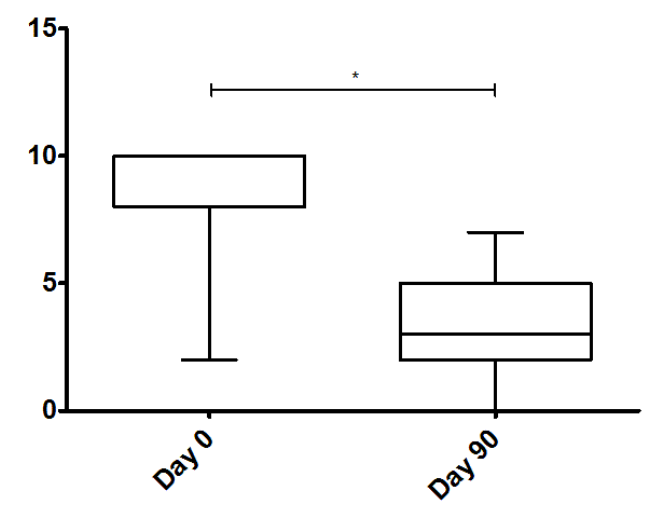

Figure 3. Visual analogue Scale in day 0 and day $90 . * \mathrm{P}<0.001$

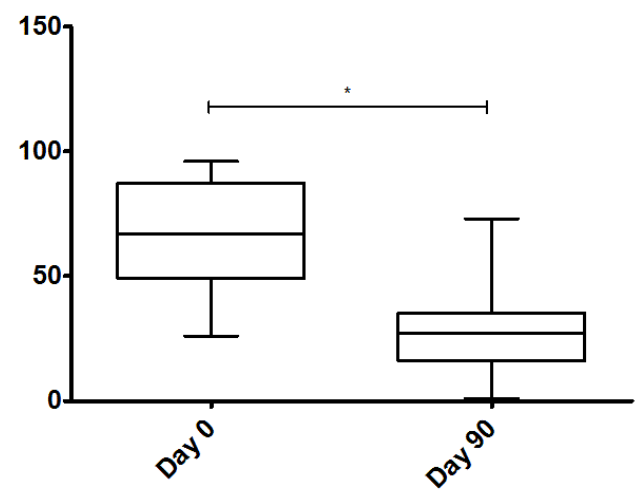

Figure 4. WOMAC index score in day 0 and day $90 . * \mathrm{P}<0.001$ 
Durán-Hernández S (2018) Clinical effect of intramuscular onabotulinumtoxinA in iliopsoas and adductor muscles in patients with coxarthrosis: A case series analysis

Table 1. Demographic and clinical characteristics of the patients

\begin{tabular}{|c|c|c|c|c|}
\hline & Female & Male & $\mathbf{P}$ & Total \\
\hline & $29(72.5 \%)$ & $11(27.5 \%)$ & $<0.001$ & $40(100 \%)$ \\
\hline Age & $61 \pm 13.7$ & $55.9 \pm 10.7$ & 0.271 & $59.6 \pm 13$ \\
\hline \multicolumn{5}{|l|}{ BMI } \\
\hline Normal weight & $6(21 \%)$ & $1(9 \%)$ & 0.65 & $7(18 \%)$ \\
\hline Overweight & $15(52 \%)$ & $6(55 \%)$ & 0.845 & $21(52 \%)$ \\
\hline Obese & $8(27 \%)$ & $4(36 \%)$ & 0.704 & $12(30 \%)$ \\
\hline \multicolumn{5}{|l|}{ Coxarthrosis } \\
\hline Grade I & $5(17 \%)$ & $3(27 \%)$ & 0.66 & $8(20 \%)$ \\
\hline Grade II & $14(48 \%)$ & $4(37 \%)$ & 0.723 & $18(45 \%)$ \\
\hline Grade III & $7(25 \%)$ & $2(18 \%)$ & 1 & $9(23 \%)$ \\
\hline Grade IV & $3(10 \%)$ & $2(18 \%)$ & 0.603 & $5(12 \%)$ \\
\hline \multicolumn{5}{|l|}{ Affected side } \\
\hline Right & $11(38 \%)$ & $5(46 \%)$ & 0.728 & $16(40 \%)$ \\
\hline Left & $12(41 \%)$ & $3(27 \%)$ & 0.486 & $15(38 \%)$ \\
\hline Both & $6(21 \%)$ & $3(27 \%)$ & 0.686 & $9(22 \%)$ \\
\hline
\end{tabular}

of the patients. However, none of the patients reported any such problems.

\section{Discussion}

In this pilot study, the application of BoNT-A in the iliopsoas and adductor brevis muscles appears to be an effective treatment for symptomatic coxarthrosis. Most of the patients in our sample had grade II coxarthrosis, a degree of severity that may represent an optimal time to apply BoNT-A treatment, so they can make changes in their lifestyle to delay the progression of the disease.

The treatment of symptomatic coxarthrosis with BoNT-A seems to be a promising modality to improve the quality of life of the patients as a result of the short-term results in pain amelioration and improvement in function. The proposed mechanism of this therapeutic modality [10] is an effect similar to the Voss operation [16], but instead of performing a tenotomy, the BoNT-A causes muscle relaxation, halting the vicious cycle of pain-contraction-pain. Additionally, there may be a decrease in the coupling joint strength, modifying the load axis with a resulting decrease of secondary inflammation.

It is necessary to conduct long-term follow up studies given that the therapeutic effect of BoNT-A is temporary, generally lasting 10-16 weeks. Longer follow-up periods would also help to evaluate the time needed for re-application of BoNT-A and truly evaluate the cost-benefit of BoNT-A treatment compared to other treatment options. Conservative rehabilitation treatment in patients with coxarthrosis often requires multiple sessions with various therapeutic modalities such as ultrasound, electrotherapy, and mechanotherapy, resulting in variable degrees of improvement. In some patients the pain experienced while receiving the rehabilitation treatment, makes them abandon the treatment. In more advanced disease (grade III and IV coxarthrosis), rehabilitation treatments often require additional pharmacologic interventions to achieve adequate symptom control. In some of the patients we observed radiological improvement of the disease, measured by joint space narrowing and superolateral migration of the femoral head on plain standing AP radiographs. However, this was not reported because only a small number of patients had a hip control radiographs after BoNT-A application.

This pilot study had several limitations. The lack of injection guidance method to ensure consistent targetting of the muscles is one significant limitation. We believe, however, that the vast experience of the physiatrist performing these injections partially overcomes this limitation. Additionally, the lack of control group and consistent postintervention imaging also limited some of the analysis. We expect to conduct a larger prospective study performing the injections using ultrasound guidance, measure other clinical parameters, and perform strict radiographic control to determine if the changes seen in these patients last or revert once the BoNT-A effect wears off.

\section{Conclusion}

Application of BoNT-A to the iliopsoas and adductor brevis muscles may be a safe and effective therapeutic approach in patients with symptomatic coxarthrosis, reducing pain and improving functionality without reported adverse effects. The safety of repeated BoNT-A injections is extensively supported in the medical literature. This could become a minimally-invasive therapeutic modality to improve the quality of life for patients awaiting surgery or for those who are not surgical candidates.

\section{References}

1. Zhang W, Moskowitz W, Nuki G, Abramson S, Altman RD, et al. (2008) OARSI recommendations for the management of hip and knee osteoarthritis, Part II: OARSI evidence-based, expert consensus guidelines. Osteoarthritis Cartilage 16: 5137-5162. [Crossref]

2. Hochberg MC, Altman RD, April NK, Benkhalti M, Guyatt G, et al. (2012) American College of Rheumatology 2012 recommendations for the use of nonpharmacologic and pharmacologic therapies in osteoarthritis of the hand, hip, and knee. Arthritis Care Res (Hoboken) 64: 465-474. [Crossref]

3. Pivec R, Johnson AJ, Mears SC, Mont MA (2012) Hip arthroplasty. Lancet 380: 1768 1777. [Crossref]

4. Pereira D, Peleteiro B, Araújo J, Branco J, Santos RA, et al. (2011) The effect of osteoarthritis definition on prevalence and incidence estimates: a systematic review. Osteoarthritis Cartilage 19: 1270-1285. [Crossref]

5. Matak I, Lackovic Z, Relja M (2016) Botulinum toxin type A in motor nervous system: unexplained observations and new challenges. J Neural Transm (Vienna) 123: 14151421. [Crossref]

6. Torres-Huerta JC, Hernández-Santos JR, Ortiz-Ramírez EM, Tenopala-Villegas S (2009) Botulinum toxin A for the management of pain in patients with chronic myofascial pain. Revista de la Sociedad Española del Dolor 17: 22-27.

7. Pagola I, Esteve-Belloch P, Palma JA, Luguin MR, Riverol M, et al. (2014) Predictive factores of the response to treatment with onabotulinumtoxinA in refractory. Rev Neurol 58: 241-246. [Crossref]

8. Buonocore M, Demartini L, Mandrini S, Dall'Angelo A, Dalla Toffola E (2017) Effect of Botulinum toxin on disabling neuropathic pain: a case presentation suggesting a new therapeutic strategy. PM R 9: 200-203. [Crossref] 
Durán-Hernández S (2018) Clinical effect of intramuscular onabotulinumtoxinA in iliopsoas and adductor muscles in patients with coxarthrosis: A case series analysis

9. Simpson DM, Gracies JM, Graham HK, Miyasaki JM, Naumann M, et al. (2008) Assessment: Botulinum neurotoxin for the treatment of spasticity (an evidence-based review). Neurology 70: 1691-1698. [Crossref]

10. Marchini C, Acler M, Bolognari MA, Causero A, Volpe D, et al. (2010) Efficacy of botulinum toxin type A treatment of functional impairment of degenerative hip joint: preliminary results. J Rehabil Med 42: 691-693. [Crossref]

11. Kollberg G, Lundholm G. The Vos Operation in Osteoarthritis of the Hip.

12. Kellgren JH, Lawrence JS (1963) Atlas of Standard Radiographs, Vol 2. PA: Oxford: Blackwell Scientific.
13. Wolfganag J (2008) Pictorial Atlas of Botulinum Toxin Injection. First ed. Quintessence books, 2008:117.

14. Bijur PE, Silver W, Gallagher J (2001) Reliability of the Visual Analog Scale for measurement of acute pain. Acad Emerg Med 8: 1153-1157. [Crossref]

15. Bellamy N, Buchanan WW, Goldsmith CH, Campbell J, Stitt LW (1988) Validation of WOMAC: a health status instrument for measuring clinically important patient relevan outcomes to antirheumatic drug therapy in patients with osteoarthritis of the hip or the knee. K Rheumatol 15: 1833-1840. [Crossref]

16. Mense S (2004) Neurobiological basis for the use of botulinum toxin in pain therapy. $J$ Neurol 251: I1-I7. [Crossref]

Copyright: (C2018 Durán-Hernández S. This is an open-access article distributed under the terms of the Creative Commons Attribution License, which permits unrestricted use, distribution, and reproduction in any medium, provided the original author and source are credited. 